\section{Complexes of Divalent Tellurium with Ethylenethiourea}

OLAV FOSS and SIGVARD FOSSEN

\author{
Chemical Institute, University of Bergen, \\ Bergen, Norway
}

$D^{\mathrm{i}}$ valent tellurium forms square planar complexes with thiourea ${ }^{\mathbf{1 - 3}}$. Of the two possible isomers, cis and trans, of type $\mathrm{Te}(\mathrm{tu})_{2} \mathrm{X}_{2}$ complexes where $\mathrm{tu}=$ thiourea, only one has been encountered in each case. $E . g$., the crystals of the halides and the thiocyanate $(\mathrm{X}=\mathrm{C}, \mathrm{Br}, \mathrm{I}, \mathrm{SCN})$ represent the cis isomer. In a study of similar complexes with ethylenethiourea (etu) we have not been able to isolate a chloride, $\mathrm{Te}(e t u)_{2} \mathrm{Cl}_{2}$, but have obtained at least two forms of the bromide, $\mathrm{Te}(e t u)_{2} \mathrm{Br}_{2}$, as well as an iodide and a thiocyanate; these are described below. In one of the bromides, isomorphous with the iodide, the tellurium atom lies in a centre of symmetry, and the arrangement of ligands around tellurium is thus planar trans. In the other one, tellurium is located on a twofold axis, and this form, or a possible third one, may be the cis isomer.

The ethylenethiourea complexes are stable in the solid state, but like the thiourea complexes, they hydrolyze and become black in contact with water. X-Ray data were obtained from oscillation and Weissenberg photographs; the values for axial lengths are based on $\lambda=1.542 \AA$ for $\mathrm{CuKa}$ radiation and are believed to be accurate to within $0.5 \%$.

Dibromobis(ethylenethiourea) tellurium(II), $\mathrm{Te}(\mathrm{etu}){ }_{2} \mathrm{Br}_{2}$. Two crystalline forms have been obtained pure, an orthorhombic and a monoclinic one. The former was best prepared from tellurium dioxide and ethylenethiourea in a molar ratio of $1: 6$ as follows: $1.6 \mathrm{~g}$ ( $10 \mathrm{mmoles})$ of tellurium dioxide was dissolved in $50 \mathrm{ml}$ of 48 $50 \%$ hydrobromic acid and $150 \mathrm{ml}$ of water, the solution was heated almost to boiling, and $6.1 \mathrm{~g} \mathrm{(60} \mathrm{mmoles)} \mathrm{of} \mathrm{ethylene-}$ thiourea in $60 \mathrm{ml}$ of hot water was added rapidly under stirring. From the resulting, clear solution (filtered immediately after mixing, if necessary) crystallization sets in spontaneously or on scratching of the bea ker walls, and may be hastened by occasional stirring; it should take place from hot solution since if the temperature falls below about $50^{\circ}$ some tetrakis(ethylenethiourea)tellurium(II) dibromide dihydrate may crystallize and contaminate the product. Yield, 2.6-3.8 g (53-77\%) depending on the rate of crystallization and temperature when filtering. M.p. $186^{\circ}$ (decomp.).(Found: S 13.27; $\mathrm{Te}$ 25.98. Calc. for $\mathrm{C}_{6} \mathrm{H}_{12} \mathrm{Br}_{2} \mathrm{~N}_{4} \mathrm{~S}_{2} \mathrm{Te}$ : S 13.04; Te 25.95.)

The brownish-yellow, orthorhombic crystals occur as flat prisms extended along the $c$ axis with $\{010\}$ dominant. The axial lengths are, $a=14.46 \AA, b=31.40 \AA$, $c=12.10 \AA$, and the space group, from systematic absences, is $D_{2 h}{ }^{24}-F d d d$, which has 32-fold general positions. There are 16 molecules per unit cell; density, calc. 2.38, found $2.38 \mathrm{~g} / \mathrm{cm}^{3}$. The intensity distribution: $h k l$ reflections with $h+k+l=2 n+1$ or $4 n$ in most cases markedly strongest, indicates that the tellurium atoms lie on twofold axes of symmetry.

The substance is practically insoluble in glacial acetic acid, but readily soluble in dimethylformamide to give red, stable solutions. When to a warm solution of the substance in dimethylformamide, preferably less concentrated than corresponding to saturation at room temperature, an about double volume of glacial acetic acid is added, the monoclinic form crystallizes; the orthorhombic one could not be recovered even on seeding.

The monoclinic crystals appear a little darker reddish-yellow in colour than the orthorhombic ones. M.p. $192^{\circ}$ (decomp.). (Found: S 13.16; Te 26.02.) They occur as prisms or plates extended along the $b$ axis, bounded by $\{100\}$ and $\{001\}$ with the latter dominant in most cases. The unit cell dimensions are, $a=17.30 \AA, b=5.89 \AA$, $c=15.57 \AA, \beta=120^{\circ}$, and there are four molecules per unit cell; density, calc. 2.38, found $2.38 \mathrm{~g} / \mathrm{cm}^{3}$. Systematic absences, $h k l$. when $h+k$ is odd, $h 0 l$ when $h$ is odd or $l$ is odd. These, together with the intensity distribution, perhaps best observed on oscillation photographs about the $b c$ diagonal: $h k l$ reflections with $k+l$ even generally stronger than those with $k+l$ odd, indicate that the tellurium atoms lie in symmetry centres, positions $(c)$ or $(d)^{5}$, of the space group $C_{2 h}{ }^{6}-C 2 / c$.

This has been confirmed by structure analysis ${ }^{6}$, through projections along the $b$ axis and along the $a b$ diagonal, the repeat distance along which is halved on account of the $C$-centering and thus is $9.14 \AA$. The dimensions of the planar trans $\mathrm{TeS}_{2} \mathrm{Br}_{2}$ group of the centrosymmetric molecule are: $\mathrm{Te}-\mathrm{S}=2.69 \AA$, $\mathrm{Te}-\mathrm{Br}=2.78 \AA$, and 
$\angle \mathrm{S}-\mathrm{Te}-\mathrm{Br}=90^{\circ}$ within the error. In the cis $\mathrm{TeS}_{2} \mathrm{Br}_{2}$ group of $\mathrm{Te}(\mathrm{tu})_{2} \mathrm{Br}_{2}$ the bond lengths are ${ }^{2,7}, \mathrm{Te}_{\Theta} \mathrm{S}=2.47 \quad \AA$, $\mathrm{Te}-\mathrm{Br}=3.05 \AA$; thus, thiourea ligands in trans positions to bromine, in a cis complex, exert a considerable lengthening effect on the $\mathrm{Te}-\mathrm{Br}$ bonds with corresponding shortening of the $\mathrm{Te}-\mathrm{S}$ bonds.

The bis(ethylenethiourea) complexes can be obtained also from tetrakis(ethylenethiourea)tellurium(II) dibromide dihydrate: A $0.01 \mathrm{M}$ solution of this salt 4 in methanol had after three days at room temperature deposited crystals of the monoclinic form. In another, like experiment, the orthorhombic form separated, and it was found that crystallization of one or the other form could be directed by seeding.

The forms are practically insoluble in methanol, and are stable in contact with the mother liquor when formed from methanolic tetrakis(ethylenethiourea)tellurium(II) dibromide dihydrate, although methanol not containing a little ethylenethiourea or acid slowly becomes black in contact with the compounds, probably because of moisture. They were on the filters washed with methanol or $96 \%$ ethanol containing a few drops of concentrated hydrobromic acid, and then with ether.

If, in the procedure for the preparation of the orthorhombic form from tellurium dioxide and ethylenethiourea, a molar ratio of $1: 4$ instead of $1: 6$ is employed $(4.1 \mathrm{~g}$ ethylenethiourea in $50 \mathrm{ml}$ of water, otherwise as above) the product is not a $\mathrm{Te}(\mathrm{etu})_{2} \mathrm{Br}_{2}$ complex but a compound of apparent composition $\mathrm{Te}_{7}(\mathrm{etu})_{12}$ $\mathrm{Br}_{16}$. (Found: $\mathrm{Br}$ 38.19; $\mathrm{S}$ 11.42; $\mathrm{Te} 26.06$. Calc. for $\mathrm{C}_{36} \mathrm{H}_{72} \mathrm{Br}_{16} \mathrm{~N}_{24} \mathrm{~S}_{12} \mathrm{Te}_{7}$ : $\mathrm{Br}$ 37.63; $\mathrm{S} 11.32$; Te 26.29.) The compound forms long, reddish-

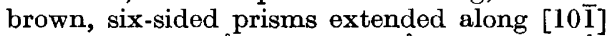
with $a=23.50 \AA, b=24.50 \AA, c=16.96 \AA$, $\beta=94^{\circ}$, and density corresponding to four formula units per unit cell; calc. 2.32 , found $2.34 \mathrm{~g} / \mathrm{cm}^{3}$. The systematic absences and the morphology indicate that the space group is $C_{2 h^{6}}-C 2 / c$, which would require that of the 28 tellurium atoms in the unit cell, 4 be located in special, fourfold positions. If the above formula is correct, and should not include two hydrogen atoms more, one of the seven tellu. rium atoms (four per unit cell) must be tetravalent.

In some early preparations, from tellurium dioxide and ethylenethiourea in a molar ratio of $1: 4$, but where smaller volumes of hydrobromic acid and water were used as solvent for the tellurium dioxide (there is then a tendency of oil formation on mixing of the tellurium dioxide and ethylenethiourea solutions) crystals of the above substance were found, admixed with crystals of orthorhombic dibromobis(ethylenethiourea)tellurium(II) and also crystals which appear to represent a third (a second monoclinic) form of the dibromo complex: Brownish yellow, long prisms or thicker, flat prisms extended along the $c$ axis, bounded by $\{100\}$ and $\{110\}$ with the former dominant, and terminated by $\{111\}$, with $a=26.76 \AA, b=$ 11.48 $\AA, c=9.38 \AA, \beta=102^{\circ}$, and density agreeing with eight $\mathrm{Te}(\mathrm{etu})_{2} \mathrm{Br}_{2}$ molecules per unit cell; calc. 2.32 , found $2.30 \mathrm{~g} / \mathrm{cm}^{3}$. The morphology indicates that a twofold axis is present, and together with the systematic ab. sences point to the space group $C_{2 h}{ }^{6}-C 2 / c$, which here would not require any molecular symmetry. These crystals could not be obtained from solutions of the orthorhombic form in dimethylformamide-glacial acetic acid on seeding; only the monoclinic trans form crystallized from such solutions.

Diiodobis (ethylenethiourea)tellurium(II), $\mathrm{Te}(\theta t u)_{2} I_{2}$, crystallizes from solutions of the salt ${ }^{4}, \mathrm{Te}_{\Theta}(\mathrm{etu})_{4} \mathrm{Cl}_{2} \cdot 2 \mathrm{H}_{2} \mathrm{O}$, in hot methanol, on addition of methanolic sodium iodide. It is readily soluble in dimethylformamide, and better developed crystals were obtained from room temperature solutions of the crude product in this solvent, by adding about four times the volume of methanol. M.p. $198-200^{\circ}$ (decomp.). (Found: S 11.17; $\mathrm{Te}$ 21.88. Calc. for $\mathrm{C}_{6} \mathrm{H}_{12} \mathrm{I}_{2} \mathrm{~N}_{4} \mathrm{~S}_{2} \mathrm{~T} \theta$ : $\mathrm{S} 10.96$; $\mathrm{T} \Theta 21.80$.

The red crystals are isomorphous with those of the monoclinic trans bromide, and show the same morphology. The unit cell dimensions are, $a=17.17 \AA, b=6.24 \AA$, $c=15.97 \AA, \beta=119 \frac{1}{2}^{\circ}$, and the density, calc. 2.61 for four molecules per unit cell, found $2.60 \mathrm{~g} / \mathrm{cm}^{3}$. From systematic absences, and isomorphism with the bromide, the space group is $C_{2 h}{ }^{6}-C 2 / c$; the tellurium atoms lie in centres of symmetry, and the $\mathrm{TeS}_{2} \mathrm{I}_{2}$ group is planar trans.

Dithiocyanatobis (ethylenethiourea)tellur$\operatorname{ium}(I I), \quad \mathrm{Te}(e t u)_{2}(\mathrm{SCN})_{2}$, was obtained from the bromide, $\mathrm{Te}(e t u)_{2} \mathrm{Br}_{2}$, and ammonium thiocyanate: $2 \mathrm{~g}$ of the bromide was dissolved by heating in a solution of $7 \mathrm{~g}$ of ammonium thiocyanate in about $20 \mathrm{ml}$ of methanol, and the resulting, red solution was allowed to cool. Yield, $0.7 \mathrm{~g}(39 \%)$. M.p. $142-144^{\circ}$ (decomp.). (Found: S 28.83; $\mathrm{Te} 28.43$. Calc. for $\mathrm{C}_{8} \mathrm{H}_{12} \mathrm{~N}_{6} \mathrm{~S}_{4} \mathrm{Te}: \mathrm{S} 28.63$; Te 28.48.)

The crystals are yellow, and form short, thick prisms $\{011\}$, with $a=10.71 \AA$, $b=12.84 \AA, c=12.01 \AA, \beta=102^{\circ}$, and

Acta Chem. Scand. 15 (1961) No. 7 
four molecules per unit cell; density, calc. 1.84 , found $1.85 \mathrm{~g} / \mathrm{cm}^{3}$. The space group, from systematic absences, is $C_{2 k}{ }^{5}-P 2_{1} / c$. No molecular symmetry is required in these crystals.

1. Foss, O. and Hauge, S. Acta Chem. Scand. 13 (1959) 1252.

2. Foss, O. and Hauge, S. Acta Chem. Scand. 15 (1961) 1615.

3. Foss, O. and Hauge, S. Acta Chem. Scand. 15 (1961) 1616

4. Foss, O. and Fossen, S. Acta Chem. Scand. 15 (1961) 1620.

5. International Tables for X-ray Crystallography, Vol. I. The Kynoch Press, Birmingham, 1952, p. 101.

6. Foss, O. and Kjøge, H. To be published.

7. Foss, O. and Maartmann-Moe, K. To be published.

Received October 8, 1961.

\section{Tetrakis (ethylenethiourea) - tellurium(II) Salts}

OLAV FOSS and SIGVARD FOSSEN

\section{Chemical Institute, University of Bergen, Bergen, Norway}

In acid solutions tetravalent tellurium reacts with six moles of thiourea to give tetrathiourea-tellurium(II) salts ${ }^{1,2}$. This note describes corresponding salts of divalent tellurium with ethylenethiourea (etu) as ligand, i.e., salts of the cation $\mathrm{T}_{\Theta}(\mathrm{etu}){ }^{2+}$. They are formed in the same way as the thiourea analogs, two moles of ethylenethiourea reducing tetravalent tellurium to divalent and thereby themselves becoming oxidized to the ethyleneformamidinium disulphide cation, (etu) ${ }_{2}{ }^{2+}$. The very soluble chloride of this disulphide cation has been described "; we have identified it in the mother liquor from tetrakis(ethylenethiourea)tellurium(II) dichloride dihydrate preparations through its reaction product 4,5 with potassium iodide.

In two salts of the $\mathrm{Te}(e t u){ }_{4}{ }^{2+}$ cation namely the anhydrous bromide and the perchlorate, and probably also in the anhydr. ous chloride, the tellurium atoms lie in centres of symmetry, and the $\mathrm{TeS}^{4}$ group is thus exactly planar, as in tetrathioureatellurium(II) salts ${ }^{\mathbf{1 , 2}}$.

Like previously described divalent tellurium complexes $1,2,6,7$, the present salts hydrolyze and liberate tellurium in presence of water. Acids prevent hydrolysis; $e . g$., the chloride and bromide can be recrystallized from $2 \mathrm{~N}$ hydrochloric and hydrobromic acid, respectively. On the filters the salts were washed with $96 \%$ ethanol containing a little concentrated hydrochloric acid (hydrobromic acid in the case of the bromides) and then with ether.

The following tetrakis(ethylenethiourea)tellurium(II) salts have been characterized through single-crystal $\mathrm{X}$-ray photographs, using Cu $K a$ radiation, $\lambda=1.542 \AA$; values for axial lengths are probably accurate to within $0.5 \%$. The salts are yellow, the chlorides with a greenish, the perchlorate with a brownish tinge.

Dichloride dihydrate, $\mathrm{Te}(\mathrm{etu})_{4} \mathrm{Cl}_{2} \cdot 2 \mathrm{H}_{2} \mathrm{O}$. To $1.6 \mathrm{~g}$ (10 mmoles) of tellurium dioxide dissolved in $15 \mathrm{ml}$ of concentrated, warm hydrochloric acid were added $6.5 \mathrm{~g}$ (a little more than 60 mmoles) of ethylenethiourea in $60 \mathrm{ml}$ of hot water. Crystallization takes place on cooling to room temperature. Yield, $6.1-6.3 \mathrm{~g}(93-98 \%)$. (Found: S 19.90; $\mathrm{Te} 19.84$. Calc. for $\mathrm{C}_{12} \mathrm{H}_{28} \mathrm{Cl}_{2} \mathrm{~N}_{8} \mathrm{O}_{2} \mathrm{~S}_{4} \mathrm{Te}$ : $\mathrm{S} 1$ 19.94; $\mathrm{Te}$ 19.84. Weight loss after one hour at $110^{\circ}: 5.8 \%$. Calc. for dihydrate: $5.6 \%$.) Prisms, extended along the $b$ axis and bounded by $\{100\},\{001\}$ and $\{101\}$, with $a=18.22 \AA, b=7.84, c=21.30 \AA$, $\beta=124^{\circ}$, and four formula units per unit cell; density, calc. 1.69 , found $1.70 \mathrm{~g} / \mathrm{cm}^{3}$. The space group, from systematic absences, is $C_{2 h^{5}}-P 2_{1} / c$.

This salt results also when a tellurium dioxide : ethylenethiourea molar ratio of $1: 4$ is used; $4.1 \mathrm{~g}$ ethylenethiourea in the above procedure gave $3.2 \mathrm{~g}$ yield. In the case of thiourea ${ }^{1}$, this molar ratio gives the dichloro complex, $\mathrm{Te}(\mathrm{tu})_{2} \mathrm{Cl}_{2}$.

The dibromide ditoydrate, $\mathrm{Te}(\mathrm{etu})_{\mathbf{6}} \mathrm{Br}_{\mathbf{2}}$. $2 \mathrm{H}_{2} \mathrm{O}$, is isomorphous with the dichloride dihydrate, and has $a=19.12 \AA, b=$ $7.85 \AA, c=21.42 \AA, \beta=125^{\circ}$; density, calc. 1.84 , found $1.87 \mathrm{~g} / \mathrm{cm}^{3}$. The salt was prepared by dissolving $1.6 \mathrm{~g}$ (10 mmoles) of tellurium dioxide in $20 \mathrm{ml}$ of 48 $50 \%$ hydrobromic and $30 \mathrm{ml}$ of water, and adding at about $50^{\circ}$, rapidly under stirring, $7 \mathrm{~g}$ (ca. $70 \mathrm{mmoles}$ ) of ethylenethiourea in $100 \mathrm{ml}$ of warm water. The resulting, orange red solution was allowed to cool to room temperature. Yield, about 